\title{
Myocardial perfusion imaging in coronary artery disease: SPECT, PET or CMR?
}

\author{
E. E. van der Wall
}

Published online: 3 July 2012

(C) The Author(s) 2012. This article is published with open access at Springerlink.com

Noninvasive imaging in the evaluation of a wide variety of cardiovascular diseases has gained an increasing role in the diagnostic strategy in current cardiology practice [1-4]. This holds in particular for patients with myocardial ischaemia due to coronary artery disease (CAD) [5-7]. Of the present imaging modalities, single-photon emission computed tomography (SPECT), positron emission tomography (PET) and cardiac magnetic resonance (CMR) have attained a major position when it comes to myocardial perfusion imaging [8-12].

In the May 2012 issue of the Journal of the American College of Cardiology (JACC), Jaarsma et al. [13] from Maastricht University Medical Center evaluated the diagnostic accuracy of SPECT, PET and CMR for the diagnosis of obstructive CAD. Studies published between 1990 and 2010 identified by PubMed search and citation tracking were examined. A study was included if a perfusion imaging modality was used as a diagnostic test for the detection of obstructive $\mathrm{CAD}$ and coronary angiography as the reference standard (50\% diameter luminal stenosis).

Out of a total of 3635 studies, 166 articles (including 17,901 patients) met the inclusion criteria: 114 SPECT, 37 CMR, and 15 PET studies. There were insufficient publications on perfusion echocardiography and computed

E. E. van der Wall

Interuniversity Cardiology Institute of the Netherlands (ICIN) -

Netherlands Heart Institute (NHI), Utrecht, the Netherlands

e-mail: ernst.van.der.wall@icin.knaw.nl

E. E. van der Wall $(\bowtie)$

Department of Cardiology, Leiden University Medical Center,

Albinusdreef 2 Postal zone: K5-35, P.O. Box 9600, 2300 RC

Leiden, the Netherlands

e-mail: e.e.van_der_wall@lumc.nl tomography to include these modalities in the study. Patient-based analysis per imaging modality demonstrated pooled sensitivities of $88 \%$ for SPECT, $84 \%$ for PET , and $89 \%$ for CMR; pooled specificities were $61 \%, 81 \%$, and $76 \%$, respectively.

The authors concluded that SPECT, PET, and CMR all yielded high sensitivities, whereas a broad range of specificities were observed. CMR and especially PET showed a significantly higher diagnostic accuracy than SPECT. However, SPECT is more widely available, less expensive, and most extensively validated. In addition, the use of attenuation programs improved the specificity of SPECT. CMR may provide a valid alternative without ionising radiation to the nuclear imaging methods. The authors suggested that referring physicians should consider these findings in the context of local expertise and internal logistics.

The authors should be complimented for performing this impressive research. It is the first meta-analysis that has directly compared the three most commonly used techniques for myocardial perfusion imaging, i.e. SPECT, PET, and CMR. The present study emphasises that, from a clinical perspective, each of the studied imaging modalities is in principle suited for detection of abnormalities in myocardial perfusion imaging [14]. As always, selective use is mostly dependent on the institutional availability of the imaging device(s), familiarity with the technique, and the individual expert knowledge of the treating physician [15].

Open Access This article is distributed under the terms of the Creative Commons Attribution License which permits any use, distribution, and reproduction in any medium, provided the original author(s) and the source are credited. 


\section{References}

1. Rebergen SA, Ottenkamp J, Doornbos J, van der Wall EE, Chin JG, de Roos A. Postoperative pulmonary flow dynamics after Fontan surgery: assessment with nuclear magnetic resonance velocity mapping. J Am Coll Cardiol. 1993;21:123-31.

2. Henneman MM, Schuijf JD, Pundziute G, et al. Noninvasive evaluation with multislice computed tomography in suspected acute coronary syndrome: plaque morphology on multislice computed tomography versus coronary calcium score. J Am Coll Cardiol. 2008;52:216-22.

3. Groenink M, Lohuis TA, Tijssen JG, et al. Survival and complication free survival in Marfan's syndrome: implications of current guidelines. Heart. 1999;82:499-504.

4. Van de Veire NR, Schuijf JD, De Sutter J, et al. Non-invasive visualization of the cardiac venous system in coronary artery disease patients using 64-slice computed tomography. J Am Coll Cardiol. 2006;48:1832-8.

5. Bleeker GB, Mollema SA, Holman ER, et al. Left ventricular resynchronization is mandatory for response to cardiac resynchronization therapy: analysis in patients with echocardiographic evidence of left ventricular dyssynchrony at baseline. Circulation. 2007;116:1440-8.

6. van der Wall EE, Heidendal GA, den Hollander W, Westera G, Roos JP. Metabolic myocardial imaging with 123I-labeled heptadecanoic acid in patients with angina pectoris. Eur J Nucl Med. 1981;6:391-6.

7. de Roos A, Doornbos J, van der Wall EE, van Voorthuisen AE. MR imaging of acute myocardial infarction: value of Gd-DTPA. AJR Am J Roentgenol. 1988;150:531-4.
8. van der Wall EE, Vliegen HW, de Roos A, Bruschke AV. Magnetic resonance imaging in coronary artery disease. Circulation. 1995;92:2723-39.

9. Matheijssen NA, Louwerenburg HW, van Rugge FP, et al. Comparison of ultrafast dipyridamole magnetic resonance imaging with dipyridamole SestaMIBI SPECT for detection of perfusion abnormalities in patients with one-vessel coronary artery disease: assessment by quantitative model fitting. Magn Reson Med. 1996;35:221-8.

10. Kirschbaum SW, de Feyter PJ, van Geuns RJ. Cardiac magnetic resonance imaging in stable ischaemic heart disease. Neth Heart J. 2011;19:229-35.

11. Olimulder MA, Galjee MA, van Es J, Wagenaar LJ, von Birgelen C. Contrast-enhancement cardiac magnetic resonance imaging beyond the scope of viability. Neth Heart J. 2011;19:236-45.

12. Underwood SR, Bax JJ, vom Dahl J, et al. Study Group of the European Society of Cardiology. Imaging techniques for the assessment of myocardial hibernation. Report of a Study Group of the European Society of Cardiology. Eur Heart J. 2004;25:815-36.

13. Jaarsma C, Leiner T, Bekkers SC, et al. Diagnostic performance of noninvasive myocardial perfusion imaging using single-photon emission computed tomography, cardiac magnetic resonance, and positron emission tomography Imaging for the detection of obstructive coronary artery disease: a meta-analysis. J Am Coll Cardiol. 2012;59:1719-28.

14. Groothuis JG, Beek AM, Meijerink MR, Brinckman SL, Hofman MB, van Rossum AC. Towards a noninvasive anatomical and functional diagnostic work-up of patients with suspected coronary artery disease. Neth Heart J. 2010;18:270-3.

15. Lexis CP, Rahel BM, van Langen $\mathrm{H}$, et al. Cardiac magnetic resonance imaging in daily practice in a peripheral medical centre: description of the first 383 patients. Neth Heart J. 2010;18:524-30. 